\title{
LITERATURA E IMAGINACIÓN ETNOGRÁFICA
}

\author{
Fernanda ARÊAS PEIXOTO \\ Universidad de São Paulo \\ fpeixoto@uol.com.br
}

\section{$\mathrm{E}$} 1 término etnografía se refiere tanto a los caminos de la investigación como al texto escrito, indica la etimología de la palabra (del griego ethnos: gente, pueblo; y graphien: escritura). Los dos sentidos que la noción conlleva lejos de relacionarse con dimensiones o distintos momentos del hacer antropológico se asocian a un mismo movimiento de comprensión, que moviliza operaciones como observar, registrar y analizar. Así que más allá de las diferentes acepciones que la noción adquirió a lo largo del tiempo — método, técnicas, actitudes y/o crítica cultural - se puede afirmar que la etnografía es una forma de saber anclada en la experiencia, es decir, amparada en la percepción y en los sentidos y, en esa dirección, próxima a las artes. Próxima, es verdad, aunque no se confunda con ellas ya que posee un compromiso con la documentación y con la explicación que las artes, aunque puedan documentar y explicar, no poseen.

El objetivo de este texto es ensayar formas de aproximaciones entre antropología y literatura, distanciándonos de los caminos comúnmente recorridos por los intérpretes, interesados sea en las estrategias textuales de la etnografía - en la cuestión de la autoría (y de la autoridad) del texto etnográfico y en la etnografía como estilo o género literario-, sea en el análisis del «segundo libro más literario» escrito por los antropólogos (Debaenne 2010). Se trata aquí de testar otra vía de reflexión interesada en el lugar decisivo de la literatura en la composición del método y de la forma de interpretación antropológica, sin dejar de considerar por supuesto el modo en que la literatura toca el texto etnográfico.

Todo antropólogo es un escritor y un lector, y las dos actividades (escritura y lectura) integran el conjunto de las prácticas realizadas en el trabajo de campo para la elaboración del conocimiento. Lecturas diversas - técnicas, científicas y literarias - relacionadas con un proceso de interiorización de los saberes libremente interpretados, compuestos y recompuestos. Escritos varios - fichas, notas, diarios y correspondencias, como también diagramas y dibujos- que muestran los sucesivos intentos de fijar y organizar el pensamiento. Los textos literarios son una parte indispensable de la biblioteca del etnógrafo, al ofrecerle regla y compás para la construcción de hipótesis y teorías, además de 
inspiración para la composición de los escritos privados y de los textos públicos producidos por el etnógrafo.

El campo está repleto de textos (Clifford, 1998:90) que se combinan con otras formas de registro (fotografías, películas y audios), todas ellas expresiones de la etnografía al mismo tiempo que productos y artefactos del conocimiento. Textos leídos por los antropólogos, fuentes valiosas para la comprensión de los caminos de la pesquisa y de la interpretación; textos escritos por los etnógrafos en el campo que revelan los procesos de elaboración de las obras después publicadas. Las lecturas y los escritos realizados durante el trabajo de campo, incluso los de carácter más subjetivo y aparentemente distantes de la investigación, se encuentran estrechamente ligados a los modos de hacer de la pesquisa etnográfica, y funcionan no solo como un «espacio de recreación personal» (Favret-Saada, 2005: 15), sino como instrumentos y formas de reflexión.

Propongo un ejercicio breve sobre el lugar decisivo de la literatura en el interior de esas prácticas textuales - lecturas y escrituras - con la ayuda de dos ejemplos, el de Bronislaw Malinowski (18841942) y el de Michel Leiris (1901-1990), elegidos en razón de sus evidentes diferencias: como sabemos, distancias generacionales, de trayectoria y de formación separan a los autores. Y es justamente por iluminar proyectos intelectuales distintos que parecen interesantes para pensar por lo menos dos facetas de las relaciones entre antropología y literatura: la literatura impregnando el trabajo antropológico, en varias de sus etapas y dimensiones; la ciencia imprimiendo sus marcas en al hacer literario.

El ejemplo del antropólogo polaco radicado en Inglaterra nos coloca ante un compromiso científico claro e inequívoco, que toma forma en el interior de un linaje antropológico «analítico» y «pragmático», en los términos de Mary Douglas (1995), volcado al examen de reglas de parentesco y sucesión, regímenes territoriales, economía y política. El ejemplo de Michel Leiris, a su vez, evidencia los contornos que el trabajo científico adquiere en el seno de una tradición «lírica» y «expresiva» (todavía Mary Douglas ${ }^{1}$ ) que coquetea con las artes modernas en general y con el surrealismo en particular. En los dos casos, arte y ciencia se alían en el proceso de construcción del conocimiento: la literatura alimenta la imaginación antropológica mientras que la antropología proporciona caminos para la elaboración literaria. Malinowski subraya el papel de las lecturas literarias en el montaje de la interpretación y del texto; Leiris nos dirige más directamente a la composición de la escritura, equilibrada entre poesía y etnografía. Los dos casos nos ayudan a reflexionar sobre los movimientos distintos y complementarios de la lectura y de la escritura, prácticas inseparables en el taller del etnógrafo.

\footnotetext{
${ }^{1}$ La antropóloga emplea los términos para distinguir dos tradiciones, la anglosajona y la francesa, que remiten a estilos de pensamiento y formas expresivas dispares, forjadas en contextos institucionales diversos: la antropología francesa ligada a los museos y a las humanidades, la anglosajona, próxima a las ciencias sociales y a la universidad.
} 


\section{Malinowski: lecturas literarias e interpretación antropológica}

La etnografía tiene en Malinowski un marco histórico y simbólico de la instauración de la idea de trabajo de campo en la antropología, que pasa a operar a partir de entonces como elemento fundamental para la identidad de la disciplina. Si la importancia del fieldwork en la antropología británica era reivindicada antes (por Tylor y Frazer, entre otros), y ya en el siglo XIX se produjeron instrumentos para la orientación de los antropólogos en campo (el Note and queries, 1870), es con Malinowski que etnografía y antropología pasan a funcionar como términos sinónimos (Stocking Jr., 1983). Desde entonces, se estableció una forma de trabajo antropológico que incluye viajes y un contacto intensivo con las sociedades estudiadas, como se sabe, además de una buena dosis de imaginación - agrego yo- imprescindible para el desarrollo de la observación, del análisis y del registro etnográficos.

«Imagínese el lector solo, rodeado apenas de sus pertrechos, en una playa tropical cercana de una aldea nativa, viendo la lancha que lo trajo alejarse en el mar, hasta desaparecer de la vista», dice Malinowski en las célebres líneas iniciales de Los Argonautas del Pacífico Occidental (1978: 19, el subrayado es mío), en el que apela a la imaginación del lector, estableciendo el tono de su narrativa, ella misma francamente imaginativa. Malinowski estaba convencido, indica Stocking Jr., de las distancias existentes entre las observaciones realizadas y la presentación final de los resultados, y consciente de que el etnógrafo era, en última instancia, un «artífice literario». Aunque fiel a los modelos canónicos de la ciencia y a sus procedimientos, sabía que la construcción de una estructura narrativa adecuada era uno de sus grandes desafíos (Stocking Jr., 1983: 105-107). El compromiso deliberado con el montaje de la narración se revela plenamente en la tan leída y citada introducción de la monografía de 1922, en la que establece las reglas del método y el formato del texto etnográfico; texto de carácter descriptivo y fuerte efecto persuasivo.

Malinowski captura al lector desde las primeras líneas, trayéndolo de modo cómplice hacia el interior del texto en función de la forma directa como dialoga con él. En el párrafo citado arriba, y en varios otros, conversa con su lector, haciéndolo revivir la experiencia del antropólogo con el auxilio de la «ilustración concreta» de ceremonias; del montaje de escenarios al interior de los cuales se desencadena la acción; del «relato concreto» de eventos; de las imágenes plásticas de las travesías. Los llamados a la imaginación del lector se suceden en otros «imagínese» empleados y, de forma enfática, al final de la misma introducción cuando anticipa lo que su compañero y él verán juntos (el plural es decisivo): «en ellos veremos al salvaje luchando para satisfacer ciertos deseos». Y continúa: «Lo veremos forzado por una tradición de proezas heroicas y mágicas, a peligrosos y difíciles emprendimientos, atraído por su romance» (Malinowski, 1978: 34, los subrayados son míos).

La primera persona del plural, sistemáticamente utilizada, demuestra el modo como el antropólogo-narrador incluye al lector en la experiencia, como ya hemos dicho. La referencia a la «tradición de proezas heroicas» y a «su romance», a su vez, anuncia el tono de narrativas de viajes y romance de aventuras que tiene el relato, evidenciado en el fragmento mencionado y en otros de la misma introducción, cuando por ejemplo el etnógrafo se presenta como un cazador «activo y atento, 
que atrae a su caza y la sigue cautelosamente hasta la cueva de más difícil acceso» (Malinowski, 1978: 22). El capítulo décimo, dedicado a la historia de un naufragio, es un ejemplo más en este sentido, un momento en el que el antropólogo compone la narrativa con la ayuda de «informaciones concretas y de supersticiones fantásticas». Ahí, dice, «los elementos fantasiosos están de tal forma entrelazados a los hechos reales, que es difícil distinguir aquello que se puede rotular de simple ficción poéticomitológica de aquello que constituye una regla común de comportamiento, retirada de experiencias reales» (Malinowski, 1978: 182). Y el antropólogo-narrador se vale ampliamente de la contaminación de los registros en la composición del texto, mezclando pedazos de cantos mágicos, descripciones de acontecimientos y episodios vividos por él.

La frecuencia con que el autor utiliza las formas interrogativas en los comienzos del libro es un recurso adicional para destacar la alianza que deliberadamente le propone al lector, invitándolo a compartir hechos y aventuras, pero también cuestiones y problemas teóricos que se presentan a lo largo del viaje a las islas Trobriand en la forma de «digresión en la narrativa directa», como indica en el capítulo cuatro y en otros: momentos de pausa para sistematizar observaciones, presentar esbozos y esquemas teóricos.

El viaje, y la experiencia que engendra, es la condición de posibilidad de la etnografía, bien lo sabemos, pero es también un artificio retórico central del texto de Malinowski. El «tour» etnográfico, anunciado en la introducción, se inicia en los dos primeros capítulos del libro, en los que presenta el mapa de la región y sus habitantes: «vamos a imaginar que estamos navegando a lo largo del litoral sur de Nueva Guinea», dice el antropólogo, definiendo en seguida una nueva orientación: «Dirijámonos ahora hacia el norte». A lo largo de la travesía se señalan la visión de los nativos y los sentimientos nacidos del contacto con ellos: sorpresa, sensaciones e impresiones se destacan en la escritura con la finalidad de «ofrecerle al lector», insiste, una fisonomía natural y social de las poblaciones tribales visitadas (Malinowski, 1978: 38-42).

La utilización del viaje como metáfora para la narrativa antropológica había sido utilizada por Frazer en el célebre libro The Golden Bough (1890), obra responsable de la conversión a la antropología del joven graduado en física y matemática en su Cracovia natal, y que continúa acompañándolo cuando confecciona la monografía de 1922; Frazer que lo inspira en la construcción del relato como viaje y en la elaboración de las descripciones vivas y detalladas ${ }^{2}$. Si la antropología frazeriana ha sido superada por Malinowski, incluso desde el punto de vista de la producción de una nueva modalidad de escritura y de otra «ficción persuasiva» (Strathern, 2013), no me parece despropositado reafirmar las afinidades de ambos, también en razón del lugar central del arte como modelo para la composición del texto científico. En ese sentido es importante recordar el prefacio a la edición de 1911 de la obra, cuando Frazer afirma: «Dejando de lado la forma austera, pero sin perjudicar, eso espero, la substancia sólida de mi tratado científico, procuré darle al material una

2 Este punto es destacado por Thornton (1985), que examina de cerca las marcas de Frazer presentes en el texto de Malinowski, con la ayuda de los libros escritos por los dos autores y de las cartas intercambiadas. 
apariencia más artística y con eso, tal vez, atraer más lectores que podrían haber sido alejados por una disposición más rígida y sistemática» (Frazer, 1982: 16, el subrayado es mío).

Atraer lectores, defiende Frazer, para quien la ciencia no podría eludir el compromiso de divulgar sus resultados; el arte contribuiría así a despojar la escritura científica de su «austeridad» habitual, funcionando también como un repertorio de apoyo para aproximar al lector a la materia sobre la cual se inclina el científico. De esa forma, para presentar la leyenda de la rama dorada, se vale del conocido cuadro de Turner sobre el tema: «Quién no conoce el cuadro de Turner sobre la rama dorada», se pregunta en las líneas iniciales de la obra (Frazer, 1982: 20).

Frente a esas elecciones, no parece extraño que Frazer haya destacado la importancia de la literatura en la obra de Malinowski y subrayado su papel no sólo como medio de «atraer lectores», sino fundamentalmente como método. Al buscar dar cuenta de la «complejidad humana», el antropólogo y el escritor parten de la observación del comportamiento humano, dice, pero en la elaboración del texto son lanzados al camino de la abstracción, sea para la composición de los personajes y para la comprensión de la naturaleza humana (el escritor), sea para el montaje de la explicación y para la generalización teórica (el antropólogo). «El cientista, así como el literato», continúa, «tiende a ver a la humanidad solamente en abstracto, seleccionando para sus consideraciones apenas un aspecto de los muchos que caracterizan al ser humano en su complejidad» (Frazer, 1982: $6)$.

El diario de campo de Malinowski permite otro acceso para la comprensión del papel que la literatura posee en el trabajo antropológico. Ese documento póstumo muestra la práctica etnográfica inmersa en lecturas de diversos tipos: manuales (Notes and queries, 1849); obras antropológicas (la de Frazer, por ejemplo); y sobre todo textos literarios, entre ellos Maupassant, Racine, Victor Hugo, Gautier, Kipling, Fenimore Cooper, Conrad, además de romances de segunda categoría que toman una parte considerable del tiempo del investigador.

El jueves comencé a leer Bragelonne [El vizconde de Bragelonne, de Alejandro Dumas], y lo leí literalmente sin interrupción, hasta la noche del miércoles o del martes [...]. Comenzaba a leer cuando me levantaba, no paraba ni a la hora de comer, y continuaba hasta la medianoche. Solo en el ocaso salía arrastrándome de la cama para hacer una breve caminata por el litoral. La cabeza me zumbaba, los ojos y el cerebro estaban $[\ldots]$ — e incluso así continuaba leyendo, leyendo e insistía en leer sin descanso como si me estuviese leyendo a mí mismo hasta la muerte» (Malinowski 1985: 96).

Las lecturas literarias, lejos de reducirse a momentos de fuga del trabajo, reverberan en el estilo de las monografías de Malinowski, ayudándolo aún a componer el método y la propia forma de la interpretación, enseñan Frazer y también Carlo Ginzburg en el ensayo «Tusitala y su lector polaco» (2000) que, entre otras virtudes, ayuda a desplazar la aproximación corriente entre Conrad y Malinowski (Stocking Jr., 1974; Clifford, 1995)³. Tomando como base del análisis el diario y también la correspondencia del antropólogo con su novia y después esposa, Elsie Masson, el historiador italiano sigue los rastros del Malinowski-lector, y defiende la importancia decisiva que «El diablo de la botella»

\footnotetext{
${ }^{3}$ Firth indica que el propio Malinowski había declarado sus afinidades con Conrad: «Mrs. B. Z. Seligman me ha contado que Malinowski dijo una vez orgullosamente: Rivers es el Rider Haggard de la antropología: yo seré el Conrad» (1974: 7).
} 
de R. L. Stevenson tiene en la visión proyectada por el antropólogo sobre el sistema de intercambio trobriandés (el Kula) como una totalidad dotada de sentido. Malinowski recibe de la novia el volumen de cartas de Stevenson, que tanto lo fascinó, sobre todo las descripciones que el escritor hace de Samoa y de Honolulu, que reflejan la propia experiencia del etnógrafo en aquel momento: un «civilizado» en el medio de la «extrañeza exótica de su nueva existencia». No se puede probar que el antropólogo haya leído el cuento de Stevenson (traducido para el samoano y recibido con gran entusiasmo), pero parece plausible considerar que sí, señala Ginzburg (2000: 108). En «El diablo de la botella», observa,

\begin{abstract}
[...] Malinowski habría encontrado la descripción novelesca de un intercambio monetario caracterizado por el perjuicio, vinculado a imposiciones simbólicas precisas que permitían la circulación de un objeto de mucho valor por una serie de islas dispersas en una enorme extensión del océano. Es evidente la analogía entre esta descripción y la imagen compleja del kula formada por el etnógrafo, tan diferente de la percepción parcial de los actores implicados. Lo que el cuento de Stevenson podría ofrecerle a Malinowski era obviamente menos el contenido de su descubrimiento que la capacidad de verlo como un todo, como una Gestalt, gracias a un salto imaginativo: la capacidad de construirlo, como escribe Malinowski más tarde «más o menos como un físico construye su teoría a partir de datos experimentales» (Ginzburg, 2000: 109).
\end{abstract}

Imaginación científica y literaria se presentan como términos inseparables en el interior de la antropología científica defendida por Malinowski, enseña Ginzburg; una antropología que se beneficia de la literatura en pos de la elaboración de la narrativa, es cierto, y fundamentalmente para la propia interpretación.

\title{
Michel Leiris: etnografía y escritura literaria
}

Al contrario de Malinowski que posee una formación en el campo de las ciencias, Leiris es un poeta de extracción surrealista, uno más de los que llegan a la etnología en función de los primitivismos artísticos que rondan la escena francesa de los años 1920. En su caso, la fascinación por las otras culturas da lugar a la profesionalización como antropólogo, propiciada por el cargo de secretarioarchivista de la misión etnográfica y lingüística Dakar-Djibouti (1931-1933), una investigación extensiva que atraviesa el continente africano de la costa atlántica al golfo de Adén, en las puertas del mar Rojo.

Si el viaje representa el bautismo del etnógrafo, la aproximación a la antropología se construye, poco a poco, gracias a la amistad con Georges Bataille; a los cursos de Marcel Mauss; a las primeras lecturas en el área, y sobre todo a las artes que despiertan su interés, y el de otros de su generación, por los pueblos y culturas distantes. La experiencia como secretario de redacción de la revista Documents, de la que salen quince números entre 1929 y 1931, es un elemento más en el proceso de conversión de Leiris a la etnología ya que le permite un contacto próximo con las colecciones etnográficas guardadas en el Trocadéro y con sus principales incentivadores, entre los que están Georges Henri-Rivière y Paul Rivet. Es también en las páginas de la revista donde prueba una nueva modalidad de escritura que se vuelca a las cosas del mundo: objetos, formas, documentos. En ese contexto, recibe la invitación de 
Marcel Griaule para integrar la misión Dakar-Djibouti, una oportunidad para aproximarse al África que ya poblaba su imaginación por medio de imágenes que circulaban en la Europa de posguerra ${ }^{4}$.

La elección del oficio se relaciona también con el tratamiento psicoanalítico iniciado en $1925^{5}$. Psicoanálisis y antropología se asocian dando origen a una nueva forma expresiva que a partir de ese momento pasa a constituir el eje central de su obra: la autobiografía ${ }^{6}$. Así como Bataille había escrito Histoire de l'aeil (1928) bajo el impacto del tratamiento con Adrián Borel, Leiris produce L'âge d'homme (1939) — no por casualidad dedicada a Bataille — bajo los efectos del proceso analítico. La autobiografía de 1939 la escribe al mismo tiempo que Áfrique fântome (1934), un libro decididamente experimental que ensaya una fuerte articulación entre antropología y literatura. «Ahí, no existe un corte entre mi trabajo como etnógrafo y mi actividad como escritor», afirma (Leiris \& Corpet 1992: 39). La escritura de sí, ejercitada hasta entonces en el diario que mantiene entre 1922 y 1989 (Leiris, 1992a), adquiere ahora una dimensión pública: se presenta como un proyecto literario concebido y realizado en el mismo momento en el que elige la ciencia como oficio.

Si la imaginación literaria impregna el trabajo científico-antropológico de Malinowski, la forma de la narrativa y de la interpretación, el método etnográfico alimenta el trabajo del escritor, indica Leiris cuando declara haber aprendido a utilizar fichas para registrar elementos autobiográficos durante la travesía africana. En este sentido, la empresa autobiográfica está marcada por la práctica del archivista, en la base de la construcción de Afrique fântome, de L'âge d'homme y de La règle du jeu, obras que se benefician de la organización y el manoseo de fichas, experimentadas por primera vez durante el viaje etnográfico (Leiris, 1992b: 49).

Es posible decir que las investigaciones (de sí y del «otro») dan origen a archivos (personales, históricos y culturales) que se transforman en textos; textos, ellos mismos, que son como las colecciones: acumulan hechos, impresiones, restos de memorias. Así que la práctica de la observación y de la descripción que el trabajo etnográfico exige, completa y amplía la tarea de observación y descripción de sí, ejercitada por el tratamiento psicoanalítico.

El afán por un registro exhaustivo preside la composición del diario de viaje africano, editado antes de las monografías La langue secrète des Dogons de Sanga y La possession et ses aspects théâtraux chez les Ethiopiens de Gondar, de 1948 y 1958, respectivamente. En este sentido, Leiris contraría el orden de las publicaciones (los diarios o el «segundo libro» más literario de los antropólogos tienden a aparecer después de las monografías científicas ${ }^{7}$ ) y las convenciones de su

\footnotetext{
${ }^{4}$ La ruptura con el surrealismo, con el Partido Comunista y el casamiento con Louise Godon (Zette) son otros factores que impulsan al joven poeta en dirección de la etnología y que lo llevan - como indican varios de sus intérpretes- a una fase más realista y menos surrealista de su producción. Lo que no significa desconsiderar los trazos profundos que procedimientos ejercitados en el período surrealista (el registro de sueños, la descomposición de palabras y el collage) dejan en su producción posterior.

5 «Ce n'est pas grâce à la psychanalyse que j'ai écrit, j'écrivais déjà. Mais c'est grâce à elle que, au retour de la mission Dakar-Djibouti, j'ai été assez raisonnable pour faire une licence de lettres et puis m'installer, si je puis dire, dans la profession d'ethnologue» (Leiris, 1992a: 52). Sobre el asunto véase também L'âge d'homme (1939), sobre todo la última parte, «Le radeau de la Méduse».

${ }^{6}$ Recordemos Le sacré dans la vie quotidienne (1938), L'âge d'homme (1939) y los cuatro volúmenes de La regle de jeu (publicados entre 1948 y 1976).

${ }^{7}$ Sobre este punto ver Jamin (1996: 71) y Debaene (2010: 271).
} 
tiempo, por medio de un estreno poco común en el universo científico de la época que, no por acaso, recibe con reservas el libro de $1934^{8}$. Así que cuando ingresa al universo de la ciencia, Leiris conjuga expresamente las dos modalidades de escritura y los dos oficios (el de etnógrafo y el de escritor) que después se esforzará en separar, tanto desde el punto de vista de la producción -elabora las monografías académicas sobre la posesión y las sociedades secretas Dogon según los parámetros científico-académicos de la época ${ }^{9}$ - como de su sistemática de trabajo: produce la obra etnológica en el Museo del Hombre; la poética y autobiográfica, en su departamento y después en su casa de campo, en Saint-Hilaire; y escribe el Journal en el cuarto de dormir (Jamin 1992: 13; Leiris \& Armel, 1992: 12).

Entre el tono poético y el documental, Afrique fântome se alimenta de las experiencias vividas antes (el surrealismo, la literatura, las artes plásticas, la política) que se mezclan con las descripciones etnográficas en el relato. Si la inestabilidad es característica de la autobiografía y de la literatura de viajes - equilibradas precariamente entre lo histórico y lo ficcional - la indecisión entre los géneros queda claramente enfatizada en el diario africano bajo la forma de un juego permanente entre la confesión y el relato científico-descriptivo. Imaginación etnográfica y literaria figuran ahí como dos facetas de un mismo proyecto, una alimentando a la otra desde el punto de vista de los procedimientos.

Estamos ante un ejemplo en cierto modo opuesto al de Malinowski respecto al tipo de trabajo de campo realizado y a la forma asumida por el diario. En el caso del antropólogo polaco, se trata de una pesquisa intensiva anclada en el aprendizaje de la lengua, en la inmersión en la cultura nativa y en el ejercicio de la observación participante, en función de la prolongada estadía entre los trobriandeses ${ }^{10}$. El diario, en este caso, más que un texto que busca la divulgación, es un escrito privado, uno de los instrumentos del trabajo de pesquisa. Michel Leiris nos presenta otro modelo de diario de campo (producido desde el principio con vistas a la edición ${ }^{11}$ ) y de investigación antropológica, más próxima a la expedición científica y a los métodos extensivos, cuyo objetivo primero es la recolección de objetos para los museos de la época. Sin embargo, su modelo es Malinowski: confiesa que al partir espera que su trabajo en la misión Dakar-Djibouti pueda ser «tan interesante como el de Malinowski» (apud Jamin, 1996: 68).

\footnotetext{
${ }^{8}$ El libro se edita sin pasar por la apreciación de Griaule, lo que le trae problemas con el jefe de la misión y también con el medio etnológico más amplio (Mauss y Rivet), que reciben la obra con grandes reservas y la consideran inoportuna para la investigación etnográfica (apud Jamin 1996: 71).

${ }^{9}$ En el comienzo de «La croyance aux génies 'zâr' en Éthiopie du Nord», publicado originalmente en 1938, afirma: «Il s'agit ici d'une simple présentation de documents. Je ne permettrai donc que le minimum d'interprétation personnelle et je ne mettrai jamais en œuvre que mes propres observations, avec les réflexions ou commentaires qui ont été fournis par les informateurs indigènes» (Leiris, 1989: 11).

${ }^{10}$ Malinowski estuvo entre los Mailu de la isla de Tulón, de septiembre de 1914 a marzo de 1915, sobre ellos publicó una pequeña monografía. En seguida, se estableció en las islas Trobriand, donde permanece de junio de 1915 a mayo de 1916; después, de octubre de 1917 a octubre de 1918.

${ }^{11}$ Consciente de los riesgos implicados en la forma y el contenido del relato, Leiris se lo muestra solamente a su mujer y le encarga que encuentre un editor para el texto (Jamin 1996: 70). Así como Elsie había sido la destinataria de las cartas enviadas por Malinowski desde el campo, Zette se convierte en la principal interlocutora de Leiris durante el viaje etnográfico.
} 
Si las lecturas literarias son una parte fundamental del trabajo etnográfico de Malinowski, el bautismo etnográfico de Leiris muestra el campo como un espacio de amplia producción textual, elaborada como expresión de la experiencia vivida, del dépaysement, del encuentro con los otros pueblos y culturas y, fundamentalmente, como fruto del trabajo de la memoria. Memoria alimentada por la función desempeñada al interior de la misión Dakar-Djibouti, que hace de Leiris un «memorialista» más que un «investigador» (Jamin, 1996: 69), como también una memoria impresa en la escritura etnográfica. Al final, ¿no es el registro de los acontecimientos en el diario al mismo tiempo la traducción de una experiencia única y la memoria de lo que acaba de pasar? Si es así, no parece exagerado suponer que esos registros textuales (privados), elaborados y reelaborados a lo largo de los días, funcionan como instrumentos mnemónicos capaces de retomar la experiencia vivida, reconstruirla y analizarla. Un proceso que adquiere forma en un texto final (público), capaz de hacer perenne la experiencia y de volverla memorable.

El efecto perturbador de Afrique Fântome se relaciona, entre otras cosas, con el modo como el texto borra deliberadamente las fronteras entre arte y ciencia, entre registro público y privado, entre trayectos oníricos y elaboraciones analíticas. Y más: el libro-diario se presenta como una colección de materiales heteróclitos, pasible de ser modificada y ampliada de acuerdo con las decisiones del coleccionador, que pone en escena en el conjunto reunido una determinada fisonomía. El carácter inacabado del texto, interrumpido el 16 de febrero ${ }^{12}$, subraya el gesto constante y obsesivo del sujeto, siempre listo para añadir una nueva pieza a la composición ${ }^{13}$.

Al mismo tiempo diario etnográfico, autobiografía y el primer libro de Michel Leiris como etnólogo profesional - que las innumerables descripciones etnográficas avalan-, Afrique fântome es también un archivo de experiencias, impresiones, sentimientos y recordaciones. Sin embargo, lejos de guardar una temporalidad histórica — como pretenden hacerlo nuestros archivos- el diario leirisiano la subvierte, integrando los eventos coleccionados en un sistema textual ${ }^{14}$, otro de sus efectos perturbadores.

Tal operación de subversión de la historia se realiza por la estrecha relación que el texto establece entre el pasaje del tiempo y el desplazamiento en el espacio. Es el calendario el que dicta el ritmo de la narrativa: las ciudades y lugares se suceden con las horas, los días, los meses del año, las estaciones. Pero como el viaje etnográfico no narra aventuras sino que se enraíza en la rutina, su registro frisa el tedio. El 31 de marzo de 1932, escribe: «La vida que llevamos aquí es la más monótona y burguesa. El trabajo no es esencialmente diferente al trabajo en la fábrica, en el gabinete o en la oficina» (Leiris, 1996: 391). La uniformidad enfatizada exhaustivamente tiene como efecto la paralización del tiempo: no acontece nada, hay siempre un carro que se atasca, una partida postergada, un descubrimiento

\footnotetext{
${ }^{12}$ «Il ne me reste rien à faire», dice en las líneas finales del diario, «sinon clore ce carnet, éteindre la lumière, m'allonger, dormir, —et faire des rêves...» (Leiris, 1996: 868).

${ }^{13}$ Italo Calvino muestra las relaciones entre diario y colección en una dirección inversa; toda colección, dice, es un diario, «diario de viaje, claro, pero también diario de sentimientos, de estados de ánimo, de humores» (Calvino, 2010: 13).

${ }^{14}$ Aquí la inspiración es la reflexión de Lévi-Strauss sobre los churinga aranda que presentan, según el autor, analogías con nuestros documentos de archivos en la medida en que integran eventos a estructuras (cf. «Le temps retrouvé», en $L a$ pensée sauvage, 1962).
} 
frustrado, una sensación de inmovilidad flotando en el aire. El presente que el viaje impone, y que el diario destaca, aparece como una reposición continua del día anterior.

El rechazo del tiempo se presenta como una tarea declarada en la autobiografía del autor, L'âge d’homme (1939). En ella el tiempo, plásticamente representado por imágenes, es la antítesis de cualquier tipo de cronología. ¿Y de qué hablan las imágenes coleccionadas en este caso? De la experiencia del envejecimiento, del aprendizaje del cuerpo, de una pedagogía del amor y de la muerte. Escribir para suprimir el tiempo, controlar el futuro y vencer a la muerte, esa es la motivación confesa del autor.

El viaje aparece como otro recurso para lidiar con el mismo propósito, en función de la articulación que engendra entre tiempo y espacio. «En cuanto a mí», dice en la víspera de la partida, «veo el viaje - además de como el mejor método para adquirir un conocimiento real, es decir, vivosobre todo como la realización de ciertos sueños de infancia y, al mismo tiempo, un medio de luchar contra la vejez y contra la muerte, lanzándome al espacio para escapar imaginariamente a la marcha del tiempo» (Leiris, 1992c: 1993). Una tentativa de fijar la experiencia en la escritura, Áfrique fântome es también y fundamentalmente un intento por retener el curso del tiempo.

Si las lecturas literarias no dejaron de acompañar al Leiris-etnólogo, su ejemplo acentúa el lugar primordial de las escrituras en el interior del trabajo etnográfico. Escritos plurales que se muestran en su heterogeneidad e incompletud en el diario africano, diario que deja al desnudo los gestos vacilantes y los sentimientos ambivalentes del antropólogo-escritor. El libro tiene aún el mérito de subrayar en su propia forma el carácter siempre provisorio de la creación literaria y científica.

\section{Referencias bibliográficas}

CAlvino, I. (2010): «Coleção de areia», en Coleção de areia. Trad. Maurício Santana Dias. São Paulo, Companhia das Letras.

ClifFORD, J. (1995): «Sobre la invención etnográfica del sujeto: Conrad y Malinowski», en Dilemas de la cultura. Antropología, literatura y arte en la perspectiva pós-moderna. Trad. Carlos Reynoso Barcelona, Gedisa, pp. 119-146.

DebAene, V. (2010): L'adieu au Voyage. L'ethnologie française entre science et littérature. París, Gallimard.

Douglas, M. (1995): «Réflexions sur le renard pâle et deux anthropologies: à propos du surréalisme et de l'anthropologie française», en C. W. ThOMPSON, L'autre et le sacré. Surréalisme, cinéma, ethnologie. París, L'Harmattan, pp. 199-218.

FAVRET-SAADA, J. (2005): «Être afecté», Gradhiva, 8, pp. 3-9.

FIRTH, R. (1974): «Introducción», en Hombre y cultura. La obra de Malinowski. Madrid, Siglo XXI.

FrAZER, J. G. (1890): O ramo de ouro. Ed. Mary Douglas. Trad. Waltensir Dutra. Rio de Janeiro, Zahar, 1982. 
GINZBURG, C. (2000): «Tusitala e seu leitor polonês», en Nenhuma ilha é uma ilha. Quatro visões da literatura inglesa. Trad. Samuel Titan Jr. São Paulo, Companhia das Letras, pp. 91-114.

JAMIN, J. (1992): «Présentation», en LEIRIS (1992a), pp. 9-25. - (1996): «Introduction à Miroir de l'Afrique» en LEIRIS (1996), pp. 65-86.

LEIRIS, M. (1934): L'Afrique fântome, en LEIRIS (1996), pp. 101-868. (1938): «Le sacré dans la vie quotidienne», La Nouvelle Revue Française, 298, pp. 26-38. (1939): L'âge d'homme. Précédé de la littérature considéré comme une tauromachie. París, Gallimard, 1946.

(1989): La possession et ses aspects théâtraux chez les Ethipiens de Gondar. París, Fata Morgana.

(1992a): Journal, 1922-1989. Ed. Jean Jamin. París, Gallimard.

(1992b): C'est à dire. Entretien avec Sally Price et Jean Jamin, suivi de Titres et travaux. París, Jean-Michel Place.

(1996): Miroir de l'Afrique, Ed. Jean Jamin. París, Gallimard.

LeIRIS, M., \& CORPET, O. (1992): «Documents, Minotaure et Cie», Magazine Littéraire, 302, pp. 3239.

LEIRIS, M., \& ARMEL, A. (1992a): «Un homme du secret discret», Magazine Littéraire, 302, pp. 1727.

(1992b): «L'œil de l' ethnographe (À propos de la mission Dakar-Dijibouti)», en Zébrage. París, Gallimard, pp. 26-34.

LÉVI-STRauss, C. (1962): La pensée sauvage. París, Plon.

Malinowski, B. (1922): Os argonautas do Pacífico Ocidental. Pref. James Frazer. Trad. Anton P. Carr y Ligia A. C. Mendonça. São Paulo, Abril Cultural, 1978.

_ (1967): Journal d'ethnographe. Trad. Tina Jolas. París, Seuil, 1985.

STEVENSON, R. L. (1891): «O demônio da garrafa», en $O$ clube do suicídio. Sel. y pres. Davi Arrigucci Jr. Trad. Andréa Rocha. São Paulo, Cosac Naify, 2011.

Stocking Jr., G. (1974): «Empathy and antipathy in Heart of Darkness», en DARnELL, R., ed., Readings in the History of Anthropology. Nueva York, Harper and Row.

(1983): «The ethnographer's magic: fieldwork in British anthropology from Tylor to Malinowski», en History of Anthropology, vol. 1: Observers Observed. Essays on Ethnographic Fieldwork. Madison, The University of Wisconsin Press, pp. 70-120.

STRATHern, M. (2013): Fora de contexto: as ficções persuasivas da antropologia, seguida de comentários e respostas. Pres. y trad. Tatiana Lotierzo y L. Felipe K. Hirano. Posf. Renato Sztutman. São Paulo, Terceiro Nome.

ThORNTON, R. (1985): «"Imagine yourself set down....” Mach, Frazer, Conrad and Malinowski and the role of imagination in ethnography», Anthropology today, 1 (5), pp. 7-14. 